\title{
The role of the pharmacist in the management of type 2 diabetes: current insights and future directions
}

This article was published in the following Dove Press journal:

Integrated Pharmacy Research and Practice

16 January 2017

Number of times this article has been viewed

\section{Jeffery David Hughes' \\ Yosi Wibowo ${ }^{2}$ \\ Bruce Sunderland' \\ Kreshnik Hoti ${ }^{1,3}$}

'School of Pharmacy, Curtin University, Perth, WA, Australia; ${ }^{2}$ Centre for Medicines Information and Pharmaceutical Care (CMIPIC), Faculty of Pharmacy, Universitas Surabaya, Surabaya, Indonesia; ${ }^{3}$ Department of Pharmacy, Faculty of Medicine, University of Prishtina, Prishtina, Kosovo
Correspondence: Jeffery David Hughes School of Pharmacy, Curtin University, GPO Box U1987, Perth, WA 6845, Australia

Email J.D.Hughes@curtin.edu.au
Abstract: Type 2 diabetes is a chronic disease occurring in ever increasing numbers worldwide. It contributes significantly to the cost of health globally; however, its management remains in the most part less than optimal. Patients must be empowered to self-manage their disease, and they do this in partnership with health care professionals. Whilst the traditional role of the pharmacist has been centered around the supply of medicines and patient counseling, there is an evergrowing body of evidence that pharmacists, through a range of extended services, may contribute positively to the clinical and humanistic outcomes of those with diabetes. Further, these services can be delivered cost-effectively. This paper provides a review of the current evidence supporting the role of pharmacists in diabetes care, whilst providing a commentary of the future roles of pharmacists in this area.

Keywords: pharmacy, interventions, outcomes, benefits, glycemic control, cost-effectiveness

\section{Introduction}

Diabetes mellitus ("diabetes") is one of the fastest growing chronic diseases worldwide, and is associated with significant morbidity, mortality, and health care costs. Diabetes is characterized by high levels of glucose in the blood (hyperglycemia). There are three main types of diabetes:

- Type 1 diabetes mellitus (T1DM) in which there is an absolute deficiency in insulin production. This disease can occur at any age, although it mostly occurs in children and young adults. ${ }^{1}$

- Type 2 diabetes mellitus (T2DM) which is associated with insulin resistance, with an initial increase in insulin secretion, however over time, beta cell death and insulin insufficiency. Although T2DM mainly occurs in people aged over 40 years old, the disease is also becoming increasingly prevalent in the younger age group. ${ }^{2,3}$

- Gestational diabetes which occurs during pregnancy. The condition usually disappears once the baby is born; however, a history of gestational diabetes increases a woman's risk of developing T2DM later in life. ${ }^{1}$

The statistics related to diabetes mellitus globally are alarming. The International Diabetes Federation (IDF) Diabetes Atlas, Seventh Edition, 2015, provides the following estimates: one in 11 adults have diabetes (416 million), nearly half (46.5\%) of adults with diabetes are undiagnosed, one in seven births are affected by gestational diabetes, 542,000 children have type 1 diabetes, and a person dies from diabetes every 6 seconds. ${ }^{4}$ Further, the IDF estimates that by 2040 , one in 10 adults (642 million) will have diabetes. ${ }^{4}$ 
Of those people with diabetes, three quarters (75\%) live in low- and middle-income countries. ${ }^{4}$ The Western Pacific region (which includes Australia) has $37 \%$ of all adults living with diabetes. This includes 100 million people in the People's Republic of China (ranked highest in number of people with diabetes), 10 million people in Indonesia (seventh highest), and 7.2 million in Japan (ninth highest). Also included in this region is the country with the highest prevalence of diabetes the Pacific Island nation of Tokelau where $30 \%$ of the adult population has diabetes. Globally, Cambodia has the lowest prevalence of diabetes at $3 \% .^{4}$

T2DM is the greatest contributor to the burden of diabetes globally accounting for up to $90 \%$ of people with diabetes worldwide. ${ }^{4}$ Further, its prevalence is increasing in all countries around the world. This increase has paralleled the global epidemic of obesity. It is estimated that since 1980 worldwide, obesity has nearly doubled. In 2008, it was estimated that there were 1.4 billion adults $(35 \%$ of those 20 years or older) who were overweight, of which over half a billion (11\%) were obese. ${ }^{5}$ Importantly, it is reported that being overweight or obese contributes significantly to the burden of diabetes (44\%), ischemic heart disease (23\%), and certain cancers (range 7\%-41\%). ${ }^{5}$ Yet, obesity is preventable, and strategies to prevent diabetes and cardiovascular disease both include the common goal to optimize peoples' weight through diet and exercise.

Adults with diabetes have a two- to threefold increased risk of suffering a heart attack or stroke compared to those without diabetes. ${ }^{6}$ The microvascular complications of diabetes mellitus make it the leading cause of preventable blindness, renal disease, and amputation in developed countries. ${ }^{6-8}$ These complications have dramatic implications for health care costs, with the total annual cost impact of diabetes in Australia estimated to be at $\$ 14.6$ billion, ${ }^{9}$ whilst globally, it is estimated to account for $12 \%$ of the global health expenditure (US\$673 billion). ${ }^{4}$ By 2040, it is estimated that the proportion of global health expenditure will exceed US\$802 billion. ${ }^{4}$

Optimizing therapy in patients with diabetes is a difficult clinical task requiring considerable patient education and motivation. The goal is to improve glycemic control without adverse bodyweight gain or hypoglycemia, and with a positive or neutral effect on lipid levels and blood pressure. Proper drug selection involves identifying the drug that is most likely to improve control and least likely to cause interactions, and adverse effect or adherence problems. Consequently, it has the potential to change patients' futures and health care systems' costs. ${ }^{10}$
Pharmacists represent the third largest health profession in the world ${ }^{11}$ after doctors and nurses. Most pharmacists work in the community with a smaller proportion in hospital pharmacy, academia, industry, and research. Community pharmacies provide a range of products (in respect to diabetes prescription and nonprescription medication, blood glucose meters and testing strips, needles and swabs, dietary supplements) and services (such as medication review, vaccination, unit dose dispensing, needle exchange, point of care testing, disposal of unwanted medicines, etc). ${ }^{12}$ Community pharmacists are considered to be the most accessible health care professionals, as no appointments are required to see them, and to have the highest level of patient contact. As such, they are well placed to play a significant role in the care of patients with T2DM.

This review discusses the health care requirements of T2DM and the current and future roles of pharmacists in its management. For the purposes of the review, papers were identified from English language PubMed and ScienceDirect databases up until October 2016, and by manually reviewing the references for the papers adjudged relevant based on title and abstract, and then full paper review. The keywords used included diabetes, pharmacist, pharmacy, intervention, glycosylated hemaglobin (HbA1c), improvement, benefit, and outcomes. Papers critiqued in this review include original research papers, together with systematic reviews and metaanalyses. The paper aims to provide an overview of the current evidence for the role of pharmacists in diabetes care and insights into what roles pharmacists may fulfill in the future.

\section{Health care for T2DM patients}

The management of those with T2DM should be seen as a partnership between the patient and health care professionals, in which the latter support the former in self-managing his or her disease. Management of every patient should commence with a detailed assessment at the initial diagnosis including an appraisal of diabetes complications and risk factors for complications. This provides the basis for continuing care that includes a treatment plan, treatment administration, monitoring, and review (Figure 1 and Table 1). ${ }^{1,13-16}$

Pharmaceutical care is defined as "the responsible provision of drug therapy for the purpose of achieving definite outcomes that improve a patient's quality of life". ${ }^{17}$ It provides a platform for multidisciplinary collaboration, which means that the pharmacist and the doctor (and potentially other care providers) join forces to decide on the optimal treatment of the patient so as to achieve the outcome the patient desires. ${ }^{18}$ It requires that a professional relationship 


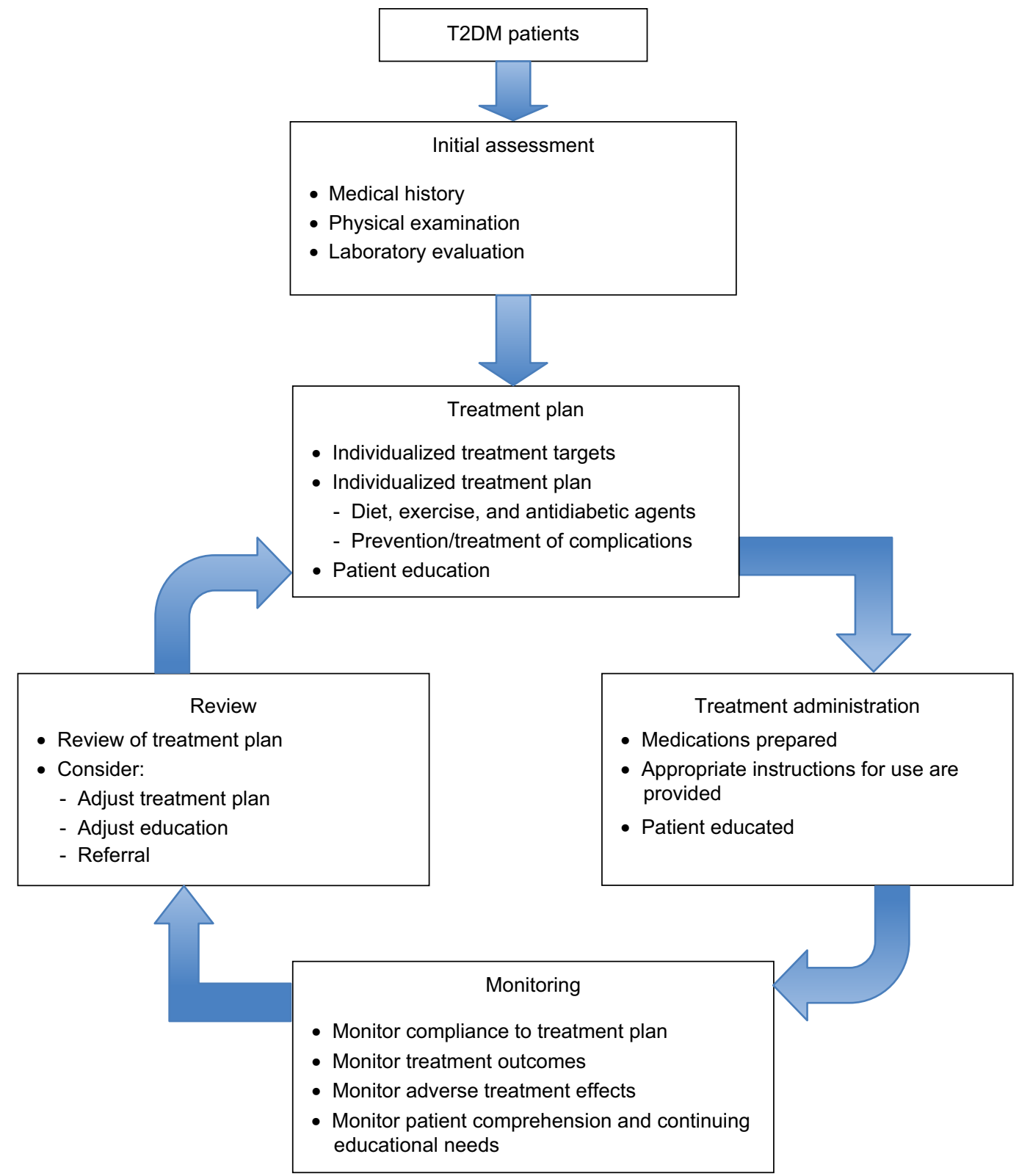

Figure I Model of care for T2DM in primary care.

Note: Data from references I and 13-15.

Abbreviation: T2DM, type 2 diabetes mellitus.

between the pharmacist and the patient is established and maintained, and records on patient's medications and other specific information are collected and evaluated. In the case of prescription medicines, a therapy plan currently needs to be developed involving the doctor and the patient; ${ }^{18}$ however, pharmacists may also provide input here.

\section{Pharmacy-based services for T2DM patients}

T2DM is one of a number of common complex conditions, including asthma, chronic obstructive pulmonary disease and heart failure, which require more time and expertise than one practitioner can reasonably provide to achieve optimal therapeutic outcomes for the patient. ${ }^{1,14}$ With the development of the concept of pharmaceutical care in which pharmacists are engaged more widely in patient care, ${ }^{18}$ the opportunity exists for pharmacists to have a greater role in the care of patients with T2DM.

\section{Evidence of the benefits of pharmacists in the care of T2DM patients}

Extensive studies worldwide have evaluated the effectiveness of pharmacy-based interventions in supporting people 
Table I Processes involved in the care of patients with T2DM

\begin{tabular}{|c|c|c|}
\hline Stage & Activity & Component \\
\hline \multirow[t]{21}{*}{ Initial assessment } & History taking & Specific symptoms of glycosuria/hyperglycemic \\
\hline & & Predisposition to diabetes, eg, age, family history, obesity, lifestyle issues (eg, smoking, \\
\hline & & diet, alcohol, physical activity, occupation) \\
\hline & & Risk factors for complications: personal or family history of cardiovascular disease, \\
\hline & & overweight/obesity, smoking, hypertension, dyslipidemia \\
\hline & & Symptoms of complications, eg, cardiovascular symptoms, neurological symptoms, renal \\
\hline & & problems, foot and eye problems \\
\hline & & Other medical conditions \\
\hline & & Medications (if any) \\
\hline & & Education (if any) \\
\hline & & $\begin{array}{l}\text { Psychosocial status, eg, attitudes about illness, expectations, resources - financial, social, } \\
\text { and emotional }\end{array}$ \\
\hline & Physical examinations & Weight/waist: BMI, waist circumference \\
\hline & & Cardiovascular system, eg, blood pressure measurement \\
\hline & & Eyes, eg, pupil dilation \\
\hline & & Feet, eg, skin condition, sensation \\
\hline & & Peripheral nerves, eg, sensation \\
\hline & & Urinalysis, eg, albumin \\
\hline & Laboratory evaluation & Glycemia: HbAlc, BGL \\
\hline & & Lipids: LDL-C, HDL-C, total cholesterol, triglycerides \\
\hline & & Renal function: plasma creatinine (eGFR), albuminuria \\
\hline & & Other tests when necessary \\
\hline \multirow[t]{20}{*}{ Treatment plan } & Individualized treatment targets & Glycemic control: BGL, HbAlc \\
\hline & & Control of risk factors for complications: lipids, blood pressure, BMI, cigarette consumption \\
\hline & & Urinary albumin excretion \\
\hline & & Physical activity \\
\hline & Development of treatment plans & Antidiabetic medications \\
\hline & & Diet \\
\hline & & Physical activity \\
\hline & & Prevention/treatment of complications \\
\hline & Patient education & Diabetes disease process \\
\hline & & Treatment targets \\
\hline & & Treatment plan \\
\hline & & Antidiabetic medicines: dosing instructions, use of insulin devices, storage \\
\hline & & requirements, special precautions, and common/important adverse effects \\
\hline & & Exercise \\
\hline & & Diet \\
\hline & & Prevention/treatment of complications, eg, foot care, smoking cessation, medications \\
\hline & & for high lipid/blood pressure levels \\
\hline & & Monitoring \\
\hline & & SMBG (using glucose meter and interpreting the results) \\
\hline & & Need for regular medical monitoring \\
\hline Treatment & Medications prepared & Dispensed in accordance with legal requirements \\
\hline \multirow[t]{2}{*}{ administration } & Appropriate instructions provided & Prescription labels on directions for use \\
\hline & & Ancillary labels (if required) \\
\hline \multirow[t]{9}{*}{ Monitoring } & Monitor compliance to treatment & Medications \\
\hline & plans & Exercise plan \\
\hline & & Diet plan \\
\hline & & Prevention/treatment plans for chronic complications \\
\hline & & Scheduled medical monitoring \\
\hline & Monitor treatment outcomes & Glycemic control: HbAlc, BGL, SMBG \\
\hline & & Control of risk factors for complications: lipids, blood pressure, BMI, cigarette consumption \\
\hline & & Presence of complications: cardiovascular system, peripheral nerves, renal, eyes, feet \\
\hline & Monitor adverse effects & Presence of adverse drug effects \\
\hline \multirow[t]{3}{*}{ Review } & Review of treatment plan based on & Consider treatment plan adjustment \\
\hline & monitoring results & Consider education adjustment \\
\hline & & Referral \\
\hline
\end{tabular}

\footnotetext{
Note: Data from references I and 13-15.
}

Abbreviations: BGL, blood glucose level; BMI, body mass index; eGFR, estimated glomerular filtration rate; HbAlc, glycosylated hemoglobin; HDL-C, high-density lipoprotein cholesterol; LDL-C, low-density lipoprotein cholesterol; SMBG, self-monitoring of blood glucose; T2DM, type 2 diabetes mellitus. 
with T2DM. Most of the studies have been conducted in developed western countries, particularly the United States of America, ${ }^{19-22}$ although examples can be found around the globe including the United Arab Emirates ${ }^{23}$ and Hong Kong. ${ }^{24}$ Fewer studies however have been conducted in low- and middle-income countries such as Nigeria, ${ }^{25}$ Iran, ${ }^{26}$ India, ${ }^{27,28}$ Brazil, ${ }^{29}$ Thailand, ${ }^{30}$ Jordon, ${ }^{31}$ Iraq, ${ }^{32}$ and Malaysia. ${ }^{33}$ The range of interventions evaluated are indicated in Table 2.

The interventions were measured for their effectiveness using the following:

- clinical outcomes, such as glycemic control, ${ }^{29,34-43}$ reduction of risk factors (such as blood pressure, lipids, and body mass index [BMI]), ${ }^{29,35,42-44}$ medication adherence, ${ }^{34,38,44-46}$ screening for complications, ${ }^{43}$ and drug-related problems identified/solved; $35,37,38,42,45$

- humanistic/social outcomes, such as quality of life, ${ }^{27,35,36,42,47}$ satisfaction, ${ }^{42,46}$ belief, ${ }^{45}$ knowledge, ${ }^{27,37,38,41,42}$ lifestyle changes, ${ }^{44}$ and self-care activity; ${ }^{47}$

- economic outcomes, such as health costs..$^{42,43}$

Table 2 Components of pharmacist interventions evaluated in T2DM

\begin{tabular}{|c|c|c|}
\hline Stage & Intervention & Component \\
\hline $\begin{array}{l}\text { Treatment } \\
\text { plan/review }\end{array}$ & $\begin{array}{l}\text { Medication } \\
\text { review }\end{array}$ & $\begin{array}{l}\text { Medication review }{ }^{27,34-36} \\
\text { Interventions based on patient } \\
\text { outcomes (pharmacotherapy } \\
\text { follow-up) }\end{array}$ \\
\hline Patient & Patient & Disease process ${ }^{27}$ \\
\hline \multirow[t]{11}{*}{ education } & education/ & Goal setting ${ }^{42}$ \\
\hline & consultation & Lifestyle: physical activity, diet ${ }^{27,42,43}$ \\
\hline & & Medication ${ }^{27,34,35}$ \\
\hline & & Psychosocial support: patient health \\
\hline & & beliefs $^{34,35}$ \\
\hline & & SMBG: blood glucose meters ${ }^{42}$ \\
\hline & & $\begin{array}{l}\text { Prevention/treatment of } \\
\text { complications: foot care, } \\
\text { smoking cessation, hypertension, } \\
\text { dyslipidemia }^{43}\end{array}$ \\
\hline & & Unspecified ${ }^{42,44,45} /$ customized content \\
\hline & & (ie, education program tailored to \\
\hline & & patient's prior knowledge) ${ }^{46}$ \\
\hline & & Patient self-management services \\
\hline \multirow[t]{5}{*}{ Monitoring } & Monitoring & Review of blood glucose results $36,37,42$ \\
\hline & treatment & Physical examination (blood \\
\hline & outcomes & pressure, weight, feet, skin) $)^{42}$ \\
\hline & & HbAlc measurement ${ }^{44}$ \\
\hline & $\begin{array}{l}\text { Monitoring } \\
\text { compliance }\end{array}$ & Adherence questionnaire ${ }^{45}$ \\
\hline \multirow[t]{4}{*}{ Other } & Partnership & Liaison with the prescribing doctor ${ }^{35,42}$ \\
\hline & with other & Referral for patient education ${ }^{42,44}$ \\
\hline & health & Referral to a specialist nurse ${ }^{44}$ \\
\hline & professionals & Referral for medical advice ${ }^{35,37,44}$ \\
\hline
\end{tabular}

Abbreviations: $\mathrm{HbAlc}$, glycosylated hemoglobin; SMBG, self-monitoring of blood glucose; T2DM, type 2 diabetes mellitus.
Blenkinsopp and Hassey ${ }^{48}$ undertook a systematic review to evaluate the effect of community pharmacy interventions in diabetes (types 1 and 2). They reviewed seven papers, three focused on glycemic control, two on adherence, and one each on patient knowledge and medication problems. Six of the studies demonstrated positive results (Table 3), with two being significant. Components of community pharmacybased interventions which appeared to contribute to effectiveness included the following: patient education/consultation about their diabetes and its treatment, medications, and lifestyle changes; and monitoring/reviewing glycemic control. ${ }^{48}$ Since that review, there have been several others which are summarized in Table 3. These systematic reviews have covered the impact of pharmacists in a number of settings from hospitals, outpatients clinics, primary (community) health centers, and community pharmacy. ${ }^{19-21,49-51}$ The results of all of the systematic reviews demonstrate support for the role of pharmacist in diabetes care across the various settings.

Collins et $\mathrm{al}^{21}$ reported that $\mathrm{HbA} \mathrm{c}$ levels decreased by an average of $0.76 \%$ based upon results of 14 trials involving 2,073 subjects and fasting blood glucose by an average $1.63 \mathrm{mmol} / \mathrm{L}$ based upon results of four trials involving 589 subjects as compared to control subjects. Aguiar et al ${ }^{19}$ undertook a meta-analysis of 22 studies which examined the effect of pharmacist interventions on glycemic control in T2DM patients. This analysis demonstrated a statistically and clinically significant reduction in $\mathrm{HbA} 1 \mathrm{c}$ of $-0.85 \%$ (95\% confidence interval $[\mathrm{CI}]:-1.06$ to $-0.65, P<0.0001$ ). When community pharmacy interventions were compared to other outpatient settings, the effect on HbA1c was similar $(-0.65 \%$ vs $-0.98 \%, P=0.08)$. Interestingly, overall, the most significant effect on $\mathrm{HbA} 1 \mathrm{c}$ was seen in those studies in which participants' baseline HbAlc was $>9 \%$. Further, the benefit derived reduced as the age of the participants increased. ${ }^{19}$

Likewise, the reviews in Table 3 have demonstrated statistically significant improvements in other clinical outcomes such as reduction in risk factors and improved medication adherence. For example, Santschi et al's ${ }^{20}$ meta-analysis demonstrated significant reductions in both systolic blood pressure (SBP) $(-6.2 \mathrm{mmHg}, 95 \% \mathrm{CI}-7.8$ to -4.2$)$ and diastolic blood pressure (DBP) $(-4.5 \mathrm{mmHg}, 95 \% \mathrm{CI}:-6.2$ to -2.8 ). Six of the 14 studies included in the analysis of SBP involved community pharmacies, with three showing significant falls of between $-5.6 \mathrm{mmHg}$ and $-20.05 \mathrm{mmHg}$. Of the two community pharmacy based trials included in the same meta-analysis which reported DBP changes, both again demonstrated a positive effect, and one of them was significant $(-3.90 \mathrm{mmHg}, 95 \% \mathrm{CI}:-7.18$ to -0.62$)$. 


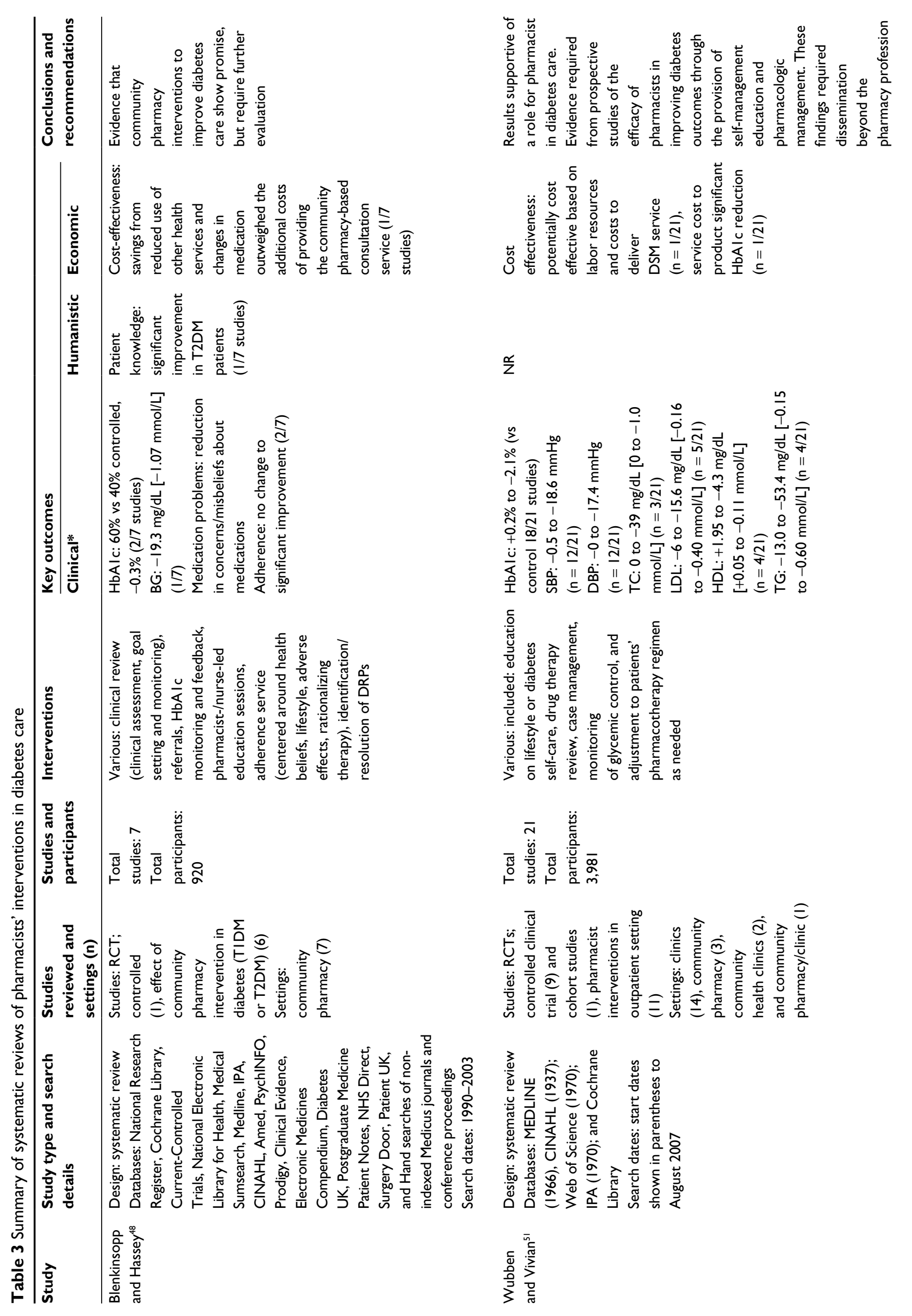


艺

$\stackrel{x}{z}$

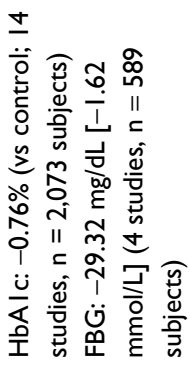

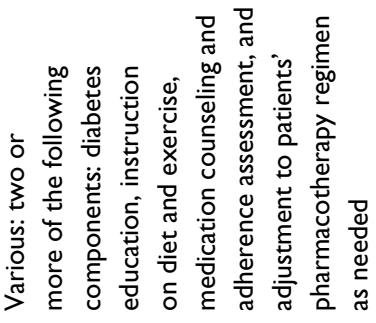

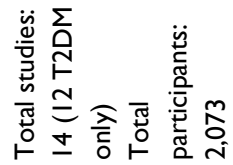

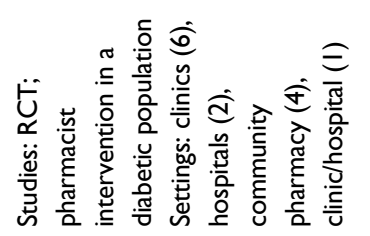

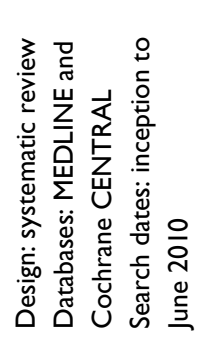

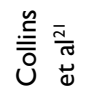

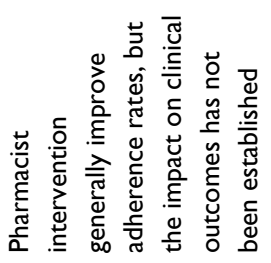

$\stackrel{\infty}{z}$

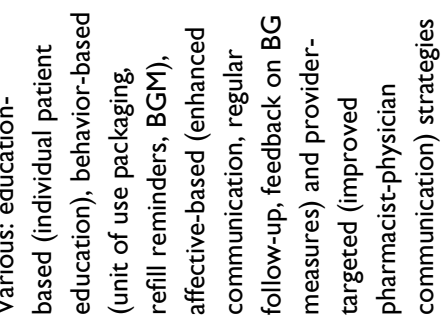

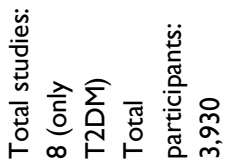
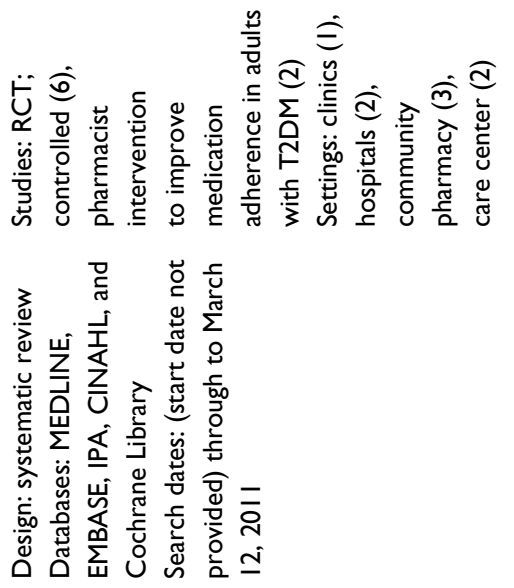

О $\stackrel{\alpha}{z}$

$\stackrel{\mathscr{N}}{z}$

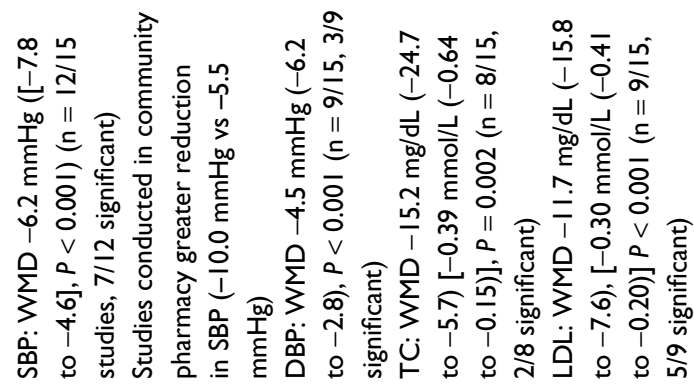
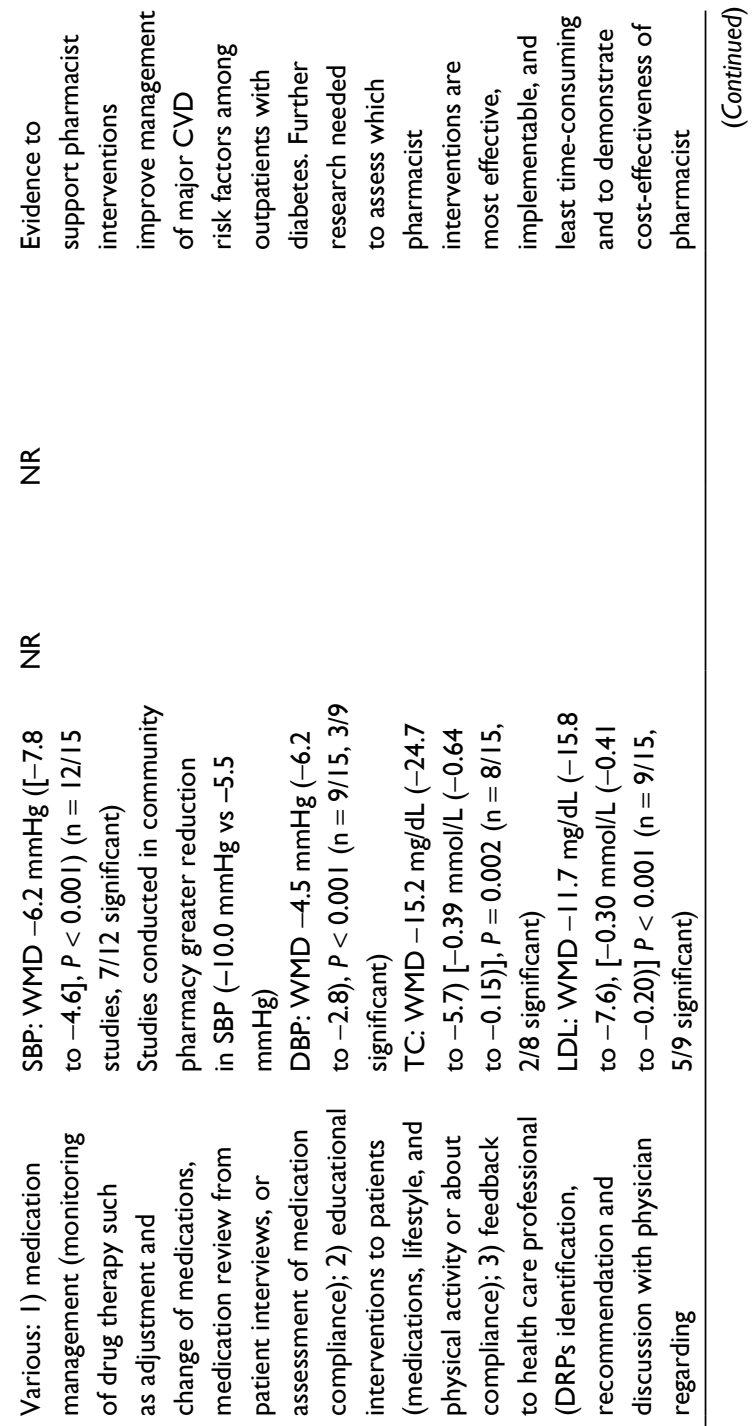

㟥站

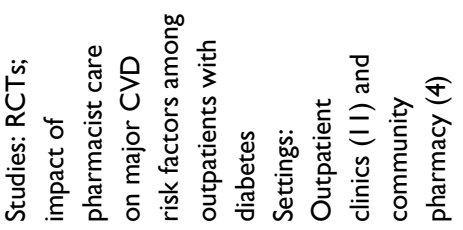

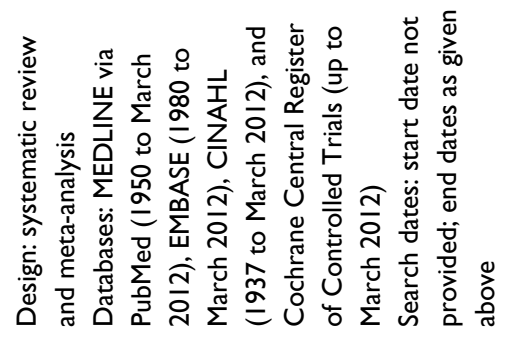

䓵 


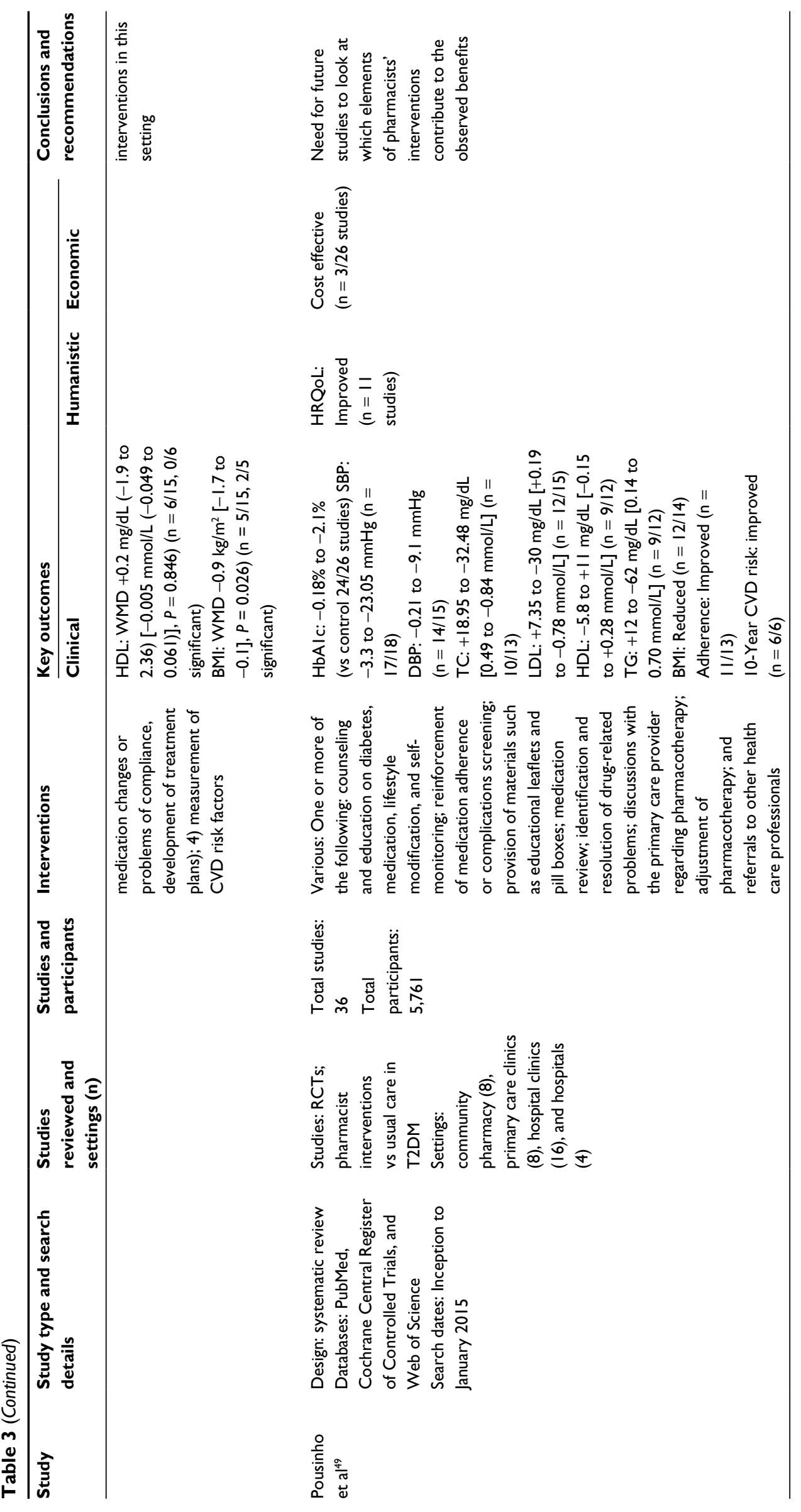




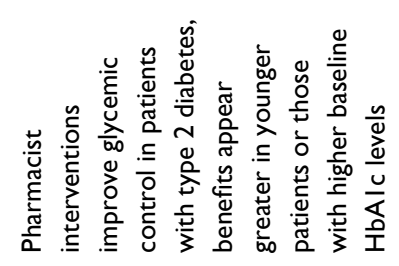

$\stackrel{\alpha}{z}$

$\stackrel{\mathscr{c}}{z}$

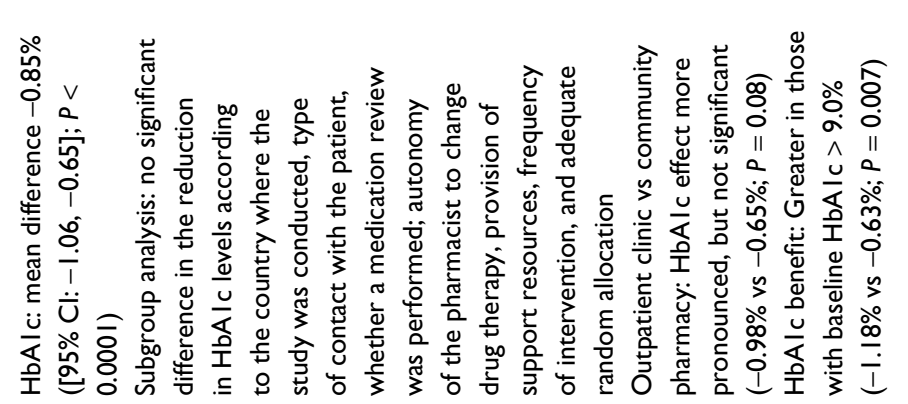

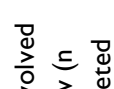

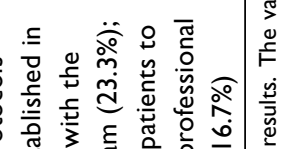

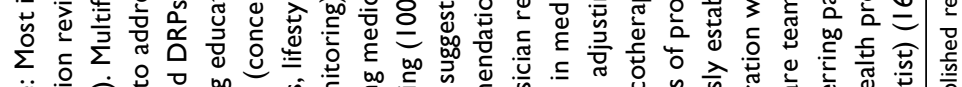

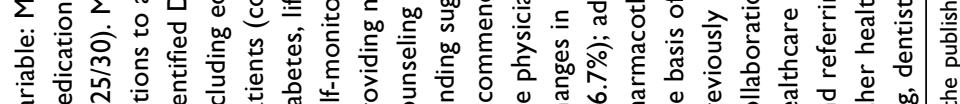

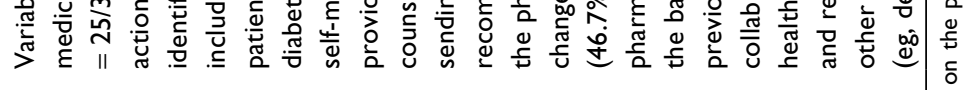

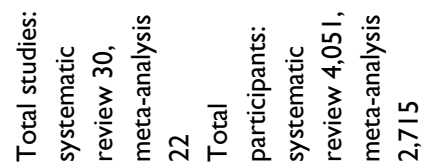

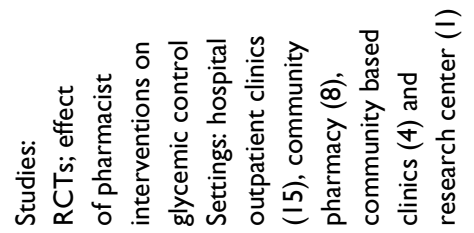

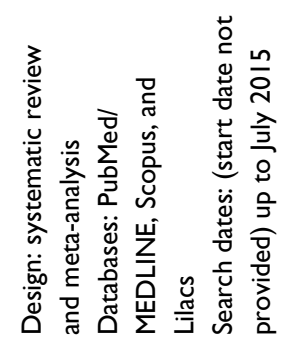

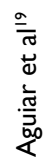

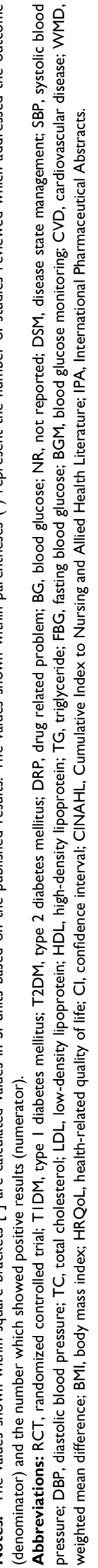


Significant reductions were also reported for total cholesterol, low-density lipoprotein cholesterol, and BMI.

Despite significant variations in the methods by which adherence was measured, pharmacist interventions were generally shown to have a positive effect, although it was unclear in many instances what impact the improvement had on clinical outcomes. ${ }^{50}$ Patients' knowledge of their disease and its complications, its treatment (pharmacological and non-pharmacological), and self-monitoring has also been shown to be increased through pharmacist-delivered educational interventions. ${ }^{51}$

The ability to demonstrate improvements in the quality of life of people with diabetes is often hampered by the short duration of the studies, and the tools chosen. Despite these factors, pharmacist-managed interventions again showed positive benefits. Limited studies have investigated the economic benefits of pharmacist interventions in diabetes care. A recent meta-analysis by Wang et al, ${ }^{22}$ which included 25 studies, reported that "pharmacist-managed services had a positive return in terms of economic viability". Ten of the 25 studies were completed in community pharmacy. Benefits demonstrated included that the average cost of a $1 \%$ reduction in $\mathrm{HbA} 1 \mathrm{c}$ was US\$174 per person; such a reduction translates into a $21 \%$ reduction in macrovascular complications. Further, whilst pharmacist interventions often increased medication costs, these costs were offset by a reduction in medical costs associated with emergency department attendances and hospitalization. ${ }^{22}$ In fact, compared to usual care, pharmacist-led services produced cost savings in the range of US\$8 to $\$ 85,000$ per year, whilst costing between US\$62,803 and US\$1 14,576 to prevent one diabetes-related macrovascular and microvascular event. Of the six studies that included cost-benefit analysis (cost-to-benefit ratio range $1: 1-8.5: 1)$, the three that were community pharmacy based were either cost neutral $(1: 1)^{52}$ or cost effective $\left(6.1: 1^{53}\right.$ and $\left.8.5: 1^{54}\right)$. Hendrie et $\mathrm{l}^{55}$ evaluated the economic benefit of reduced glycemic events (hypo- and hyperglycemia) in a group of patients who enrolled into a 6-month Diabetes Management Education Program (DMEP). They found that the intervention resulted in significantly greater reductions in the number of hyper- and hypoglycemic events relative to the control group (odds ratio [OR] 0.34, 95\% CI 0.22-0.52, $P=0.001$ vs OR $0.54,95 \%$ CI $0.34-0.86, P=0.009)$. This reduction translated into a net reduction of 1.86 days with glycemic episodes per patient per month. In terms of costeffectiveness, the DMEP costs AU\$43 (US\$39) per day of glycemic symptoms avoided relative to standard care.

In summary, to date, pharmacist interventions to improve the care of patients with diabetes, and in particular those with
T2DM, have been shown to deliver positive clinical, humanistic, and economic benefits. However, the interventions, which are often multifaceted, have varied across studies, although often education- and clinical review-based, making it difficult to determine which elements deliver the greatest benefits.

\section{Future roles for pharmacists in T2DM management}

To date, evidence supports pharmacists extending their role in diabetes care from medication supply to cognitive services which aim to assist those with diabetes achieve the best possible clinical outcomes through supporting their self-management. Realistically, pharmacists potentially have a role to play in all facets of the care of T2DM patients as depicted in Figure 1. However, widespread implementation of such services in the future will depend on legislative change, adequate funding (government and nongovernment), professional commitment, interprofessional collaboration, and consumer (patient) acceptance.

The importance of the latter should not be underestimated, with recent work again illustrating that consumers do not perceive community pharmacies as a place to go to get assistance with their diabetes care. Consumers are happy to accept that pharmacists can provide them with medications and counseling; however, they have consistent concerns about the knowledge and competency of pharmacists to provide additional services, and that community pharmacies are a suitable environment to deliver them. ${ }^{56}$ The findings of Dhippayom and Krass ${ }^{57}$ support this, with participants in their study highlighting the main role of pharmacists is medication provision, with some enhancements in supporting adherence and continuity of supply. Therefore, for community pharmacy-based services to succeed, these perceptions must be changed; this will require action from within the pharmacy profession through further training, establishment of private consulting areas, changes to workflows, and proactively promoting pharmacists' capability to deliver enhanced diabetes care.

Delivery of such services within other settings such as hospitals, outpatient clinics, and community-based clinics is likely to be better received by patients, with pharmacists being seen more as a care provider than a supplier of medicines. Evidence supports pharmacists working in these settings, either directing care or collaborating in care. ${ }^{20}$

Targeting of services to those at greatest need would seem appropriate, such as patients with newly diagnosed diabetes ${ }^{56}$ who are often overwhelmed by the diagnosis and have a poor understanding of its management. For example, general practitioners often fail to provide adequate education 
for patients starting oral hypoglycemics, and community pharmacists are well placed to fulfill this role. Further, the evidence suggests that patients with poorly managed diabetes, that is, those with $\mathrm{HbA} 1 \mathrm{c}>9 \mathrm{mmol} / \mathrm{L},{ }^{19}$ gain the greatest benefit from pharmacist interventions, suggesting targeting such patients would be appropriate. This could be facilitated through referrals from medical practitioners or pharmacists ordering of HbA1c levels or point-of-care testing.

Funding to deliver pharmacy-based cognitive services is a contentious issue, and whilst they can be funded through a user-pays model, government-funded or third-party payer models are likely to be needed for widespread implementation of such services. For example, depending on the level of remuneration, one would envisage that a limited number of community pharmacies specializing in diabetes would offer extended services. Legislative change to allow pharmacists to manage patients' diabetes therapy either in consultation with their primary health provider or independently, which has occurred in some jurisdictions, will allow pharmacists delivering such services to have greater impact.

Diabetes screening is another area of significant need which pharmacists should engage in as many people living with the disease are undiagnosed. A large-scale trial is about to commence in Australia to evaluate community pharmacists' role in diabetes screening. This study builds upon the work of Krass et al, ${ }^{58}$ which demonstrated that a sequential screening program, that is, tick test followed by capillary blood glucose testing, was an effective means to detect prediabetic and diabetic patients.

\section{Conclusion}

There is significant evidence to support the role of pharmacists in providing a range of extended diabetes care services, from the screening to ongoing disease state management. However, despite this, the provision of such services generally remains limited and inconsistent. However, this is set to change, as the number of people with T2DM grows, and the capacity of traditional care providers to cope with these people diminishes. Governments, third-party payers, and consumers will all be looking for cost-effective ways to manage diabetes. Pharmacists are ideally placed to assist patients with their diabetes management within a range of clinical settings as demonstrated by current evidence. Needed now are models of practice which are evidence based, consistent, and scalable, such that they deliver the outcomes desired by all stakeholders.

\section{Disclosure}

The authors report no conflicts of interest in this work.

\section{References}

1. American Diabetes Association. Standards of medical care in diabetes 2013. Diabetes Care. 2013;36(Suppl 1):S11-S66.

2. Pinhas-Hamiel O, Zeitler P. The global spread of type 2 diabetes mellitus in children and adolescent. J Pediatr. 2005;146(5):693-700.

3. American Diabetes Association. Type 2 diabetes in children and adolescents. Diabetes Care. 2000;23(3):381-389.

4. International Diabetes Federation. IDF Diabetes Atlas, Seventh Edition, 2015. Available from: www.diabetesatlas.org. Accessed October 28, 2016.

5. World Health Organization. Obesity and overweight. Fact sheet [updated June 2016]. Available from: http://www.who.int/mediacentre/factsheets/ fs311/en/. Accessed October 28, 2016.

6. World Health Organization. Diabetes. Fact sheet [reviewed November 2016]. Available from: http://www.who.int/mediacentre/factsheets/ fs312/en/. Accessed November 27, 2016.

7. Fowler MJ. Microvascular and macrovascular complications of diabetes. Clin Diabetes. 2008;26(2):77-82.

8. Kocur I, Resinkoff S. Visual impairment and blindness in Europe and their prevention. Br J Ophthalmol. 2002;86(7):716-722.

9. Diabetes Australia. Diabetes in Australia. 2015. Available from: https://www.diabetesaustralia.com.au/diabetes-in-australia. Accessed October 28, 2016.

10. Chloe HM, Mitrovich S, Dubay D, Hayward RA, Krein SL, Vijan S. Proactive case management of high-risk patients with type 2 diabetes mellitus by clinical pharmacist: a randomized controlled trial. Am J Manag Care. 2005;11(4):253-260.

11. FIP.org. Global pharmacy workforce and migration report: a call for action. 2016. Available from: https://www.fip.org/files/fip/publications/ PharmacyWorkforceMigration.pdf. Accessed October 28, 2016.

12. OECD.org. Health at a glance 2015. 2015. Available from: http:// www.oecd.org/els/health-systems/health-at-a-glance-19991312.htm. Accessed October 28, 2016.

13. The Royal Australian College of General Practitioners. General Practice Management of Type 2 Diabetes: 2016-18. East Melbourne, Vic: RACGP; 2016. Available from: https://static.diabetesaustralia.com.au/s/ fileassets/diabetes-australia/5d3298b2-abf3-487e-9d5e-0558566fc242. pdf. Accessed December 22, 2016.

14. Indonesian Society of Endocrinology. Consensus on the Management and Prevention of Type 2 DM in Indonesia. Jakarta: Indonesian Society of Endocrinology; 2011.

15. Power A, Douglas E, McGregor A, Hudson S. Professional development of pharmaceutical care in type 2 diabetes mellitus: a multidisciplinary conceptual model. Int J Pharm Pract. 2006;14(4):289-299.

16. Department of Health, WA, Australia. Diabetes Model of Care. Perth: Health Networks Branch, Department of Health, WA, Australia; 2008. Available from: http://www.healthnetworks.health.wa.gov.au/modelsofcare/docs/Diabetes_Model_of_Care.pdf. Accessed November 27, 2016.

17. Helper CD, Strand LM. Opportunities and responsibilities in pharmaceutical care. Am J Hosp Pharm. 1990;47(3):533-543.

18. Berenguer B, La Casa C, de la Matta M, Martin-Calero MJ. Pharmaceutical care: past, present and future. Curr Pharm Des. 2004;10(31): 3931-3946.

19. Aguiar PM, Brito Gde C, Lima Tde M, Santos AP, Lyra DP Jr, Storpirtis S. Investigating sources of heterogeneity in randomized controlled trials of the effects of pharmacist interventions on glycemic control in type 2 diabetic patients: a systematic review and metaanalysis. PLoS One. 2016;11(3):e0150999.

20. Santschi V, Chiolero A, Paradis G, Colosimo AL, Burnand B. Pharmacist interventions to improve cardiovascular disease risk factors in diabetes: a systematic review and meta-analysis of randomized controlled trials. Diabetes Care. 2012;35(12):2706-2717.

21. Collins C, Limone BL, Schoole JM, Coleman CI. Effect of pharmacist intervention on glycemic control in diabetes. Diabetes Res Clin Pract. 2011;92(2):145-152. 
22. Wang Y, Yeo QQ, Ko Y. Economic evaluations of pharmacist-managed services in people with diabetes mellitus: a systematic review. Diabet Med. 2016;33(4):421-427.

23. Al Mazroui NR, Kamal MM, Ghabash NM, Yacout TA, Kole PL, McElnay JC. Influence of pharmaceutical care on health outcomes in patients with type 2 diabetes mellitus. $\mathrm{Br} J$ Clin Pharmacol. 2009;67(5):547-557.

24. Chan CW, Siu SC, Wong CK, Lee VW. A pharmacist care program: positive impact on cardiac risk in patients with type 2 diabetes. $J$ Cardiovasc Pharmacol Ther. 2012;17(1):57-64.

25. Adibe MO, Ukwe CV, Aguwa CN. The impact of pharmaceutical care intervention on the quality of life of Nigerian patients receiving treatment for type 2 diabetes. Value Health Reg Issues. 2013;2(2): 240-247.

26. Farsaei S, Sabzghabaee AM, Zargarzadeh AH, Amini M. Effect of pharmacist-led patient education on glycemic control of type 2 diabetics: a randomized controlled trial. J Res Med Sci. 2011;16(1):43-49.

27. Adepu R, Rasheed A, Nagavi BG. Effect of patient counseling on quality of life in type-2 diabetes mellitus patients in two selected South Indian community pharmacies: a study. Indian J Pharm Sci. 2007;69(4): 519-524.

28. Venkatesan R, Devi AS, Parasuraman S, Sriram S. Role of community pharmacists in improving knowledge and glycemic control of type 2 diabetes. Perspect Clin Res. 2012;3(1):26-31.

29. Correr CJ, Melchiors AC, Fernandez-Llimos F, Pontarolo R. Effects of a pharmacotherapy follow-up in community pharmacies on type 2 diabetes patients in Brazil. Int J Clin Pharm. 2011;33(2):273-280.

30. Phumipamorn S, Pongwecharak J, Soorapan S, Pattharachayakul S. Effects of the pharmacist's input on glycaemic control and cardiovascular risks in Muslim diabetes. Prim Care Diabetes. 2008;2(1):31-37.

31. Jarab AS, Alqudah SG, Mukattash TL, Shattat G, Al-Qirim T. Randomized controlled trial of clinical pharmacy management of patients with type 2 diabetes in an outpatient diabetes clinic in Jordan. JManag Care Pharm. 2012;18(7):516-526.

32. Mahwi TO, Obied KA. Role of the pharmaceutical care in the management of patients with type 2 diabetes mellitus. Int J Pharm Sci Res. 2013;4(4):1363-1369.

33. Chung WW, Chua SS, Lai PS, Chan SP. Effects of a pharmaceutical care model on medication adherence and glycemic control of people with type 2 diabetes. Patient Prefer Adherence. 2014;8:1185-1194.

34. Berringer R, Shibley MC, Cary CC, Pugh CB, Powers PA, Rafi JA. Outcomes of a community pharmacy based diabetes monitoring program. J Am Pharm Assoc (Wash). 1999;39(6):791-797.

35. Krass I, Armour CL, Mitchell B, et al. The Pharmacy Diabetes Care Program: assessment of a community pharmacy diabetes service model in Australia. Diabet Med. 2007;24(6):677-683.

36. Armour CL, Taylor SJ, Hourihan F, Smith C, Krass I. Implementation and evaluation of Australian pharmacists' diabetes care services. J Am Pharm Assoc. 2004;44(4):455-466.

37. Fornos JA, Andrés NF, Andrés JC, Guerra MM, Egea B. A pharmacotherapy follow-up program in patients with type-2 diabetes in community pharmacies in Spain. Pharm World Sci. 2006;28(2):65-72.

38. Wermeille J, Bennie M, Brown I, McKnight J. Pharmaceutical care model for patients with type 2 diabetes: integration of the community pharmacist into the diabetes team - a pilot study. Pharm World Sci. 2004;26(1):18-25.

39. Cranor CW, Bunting BA, Christensen DB. The Asheville Project: long-term clinical and economic outcomes of a community pharmacy diabetes care program. JAm Pharm Assoc (Wash). 2003;43(2):173-184.

40. Bliss EA, Codack H, Boothe J. Diabetes care - an evaluation of a community pharmacy based HbA1c testing service. Pharm J. 2001;267: 264-266.

41. Swain JH, Macklin R. Individualised diabetes care in a rural community pharmacy. J Am Pharm Assoc (Wash). 2001;41(3):458-461.
42. Hughes J. Final report: Customised education programs for patients with diabetes mellitus - use of structured questionnaires and education modules (DMEP study). Perth: Curtin University of Technology; 2006. Available from: http://6cpa.com.au/resources/third-agreement/customisededucation-programs-for-patients-with-diabetes-mellitus-use-of-structuredquestionnaires-and-education-modules/. Accessed December 21, 2016.

43. Fera T, Bluml BM, Ellis WM, Schaller CW, Garrett DG. The diabetes ten city challenge: interim clinical and humanistic outcomes of a multisite community pharmacy diabetes care program. J Am Pharm Assoc (2003). 2008;48(2):181-190.

44. Pinto SL, Bechtol RA, Partha G. Evaluation of outcomes of a medication therapy management program for patients with diabetes. J Am Pharm Assoc (2003). 2012;52(4):519-523.

45. Krass I, Stephenson S, Thuis U, Hourihan F, Taylor S, Armour C. Increasing adherence to medications through delivery of a disease management service for Type 2 diabetes in community pharmacies. J Soc Admin Pharm. 2002;19(6):211.

46. Grant RW, Devita NG, Singer DE, Meigs JB. Improving adherence and reducing medication discrepancies in patients with diabetes. Ann Pharmacother. 2003;37(7-8):962-969.

47. Abduelkarem AR, Sackville MA. Changes of some health indicators in patients with type 2 diabetes: a prospective study in three community pharmacies in Sharjah, United Arab Emirates. Libyan J Med. 2009;4(1):31-36.

48. Blenkinsopp A, Hassey A. Effectiveness and acceptability of community pharmacy-based interventions in type 2 diabetes: a critical review of intervention design, pharmacist and patient perspectives. Int J Pharm Pract. 2005;13(4):231-240.

49. Pousinho S, Morgado M, Falcão A, Alves G. Pharmacist interventions in the management of type 2 diabetes mellitus: a systematic review of randomized controlled trials. J Manag Care Spec Pharm. 2016;22(5):493-515.

50. Omran D, Guirguis LM, Simpson SH. Systematic review of pharmacist interventions to improve adherence to oral antidiabetic medications in people with type 2 diabetes. Can J Diabetes. 2012;36(5): 292-299.

51. Wubben DP, Vivian EM. Effects of pharmacist outpatient interventions on adults with diabetes mellitus: a systematic review. Pharmacotherapy. 2008;28(4):421-436.

52. Petkova VB, Petrova GI. Pilot project for education of patients with type 2 diabetes by pharmacists. Acta Diabetol. 2006;43(2): $37-42$.

53. Bunting BA, Lee G, Knowles G, Lee C, Allen P. The hickory project: controlling healthcare costs and improving outcomes for diabetes using the Asheville project model. Am Health Drug Benefits. 2011;4(6):343-350.

54. Wertz D, Hou L, DeVries A, et al. Clinical and economic outcomes of the Cincinnati Pharmacy Coaching Program for diabetes and hypertension. Manag Care. 2012;21(3):44-54.

55. Hendrie D, Miller TR, Woodman RJ, Hoti K, Hughes J. Cost-effectiveness of reducing glycaemic episodes through community pharmacy management of patients with type 2 diabetes mellitus. J Prim Prev. 2014;35(6):439-449.

56. Twigg MJ, Poland F, Bhattacharya D, Desborough JA, Wright DJ. The current and future roles of community pharmacists: views and experiences of patients with type 2 diabetes. Res Social Adm Pharm. 2013;9(6):777-789.

57. Dhippayom T, Krass I. Supporting self management of type 2 diabetes: is there a role for the community pharmacist? Patient Prefer Adherence. 2015;9:1085-1092.

58. Krass I, Mitchell B, Clarke P, et al. Pharmacy diabetes care program: analysis of two screening methods for undiagnosed type 2 diabetes in Australian community pharmacy. Diabetes Res Clin Pract. 2007;75(3):339-347. 
Integrated Pharmacy Research and Practice is an international, peer-reviewed, open access, online journal, publishing original research, reports, reviews and commentaries on all areas of academic and professional pharmacy practice. This journal aims to represent the academic output of pharmacists and pharmacy practice with particular focus on integrated care. All papers are carefully peer reviewed to ensure the highest standards as well as ensuring that we are informing and stimulating pharmaceutical professionals. The manuscript management system is completely online and includes a very quick and fair peer-review system, which is all easy to use. Visit http://www.dovepress.com/ testimonials.php to read real quotes from published authors.

Submit your manuscript here: http://www.dovepress.com/integrated-pharmacy-research-and-practice-journal 